IFN Working Paper No. 963, 2013

\title{
Production Hierarchies in Sweden
}

\author{
Joacim Tåg
}




\title{
Production Hierarchies in Sweden
}

\author{
Joacim Tåg*
}

March 15, 2013

\begin{abstract}
I study the internal organization of firms using occupation data on workers in Swedish manufacturing firms. Firms with more layers are larger in size, in value added, and they pay higher wages. Firms are hierarchal in that lower layers have more workers and lower mean wage than higher layers. Adding layers is associated with increases in mean firm size/value added and decreases in mean firm wages (at pre-existing layers). The reverse holds for removing layers. This result also holds for layer by layer mean size and wages for a majority of pre-existing layers.
\end{abstract}

Keywords: hierarchies, organizations, occupations, wages, productivity.

JEL Classification: D22, D24, J31.

*Research Institute of Industrial Economics (IFN). E-mail: joacim.tag@ifn.se. Financial support from the Jan Wallander and Tom Hedelius Foundation and from Vinnova is gratefully acknowledged. I thank Lorenzo Caliendo, Fredrik Heyman, and Peter Thompson for outstanding comments and suggestions and Louise Johannesson for excellent research assistance. 


\section{Introduction}

Caliendo, Monte, and Rossi-Hansberg (2012)—henceforth CMRH—describe a method through which data on worker occupations can be used to construct hierarchies within firms. They use data on French production firms to provide support for central theoretical predictions from Caliendo and Rossi-Hansberg (2012) - henceforth CRH. CRH builds on the idea in Garicano (2000) and Garicano and Rossi-Hansberg (2006) that firms are hierarchies of knowledge. Production inputs are labor and knowledge, and because workers are time constrained they pass up problems they cannot solve to superiors with more knowledge. This generates hierarchies, with less knowledgable workers further down in the hierarchy. The contribution of this paper is to show that Swedish occupation data can be used to construct hierarchies as in CMRH, and that the resulting hierarchies support the theorethical predictions in CRH that:

1. Firms with more layers are larger in size, in value added, and pay higher wages.

2. Firms are hierarchal: lower layers have more workers and lower mean wages than higher layers.

3. Adding layers is associated with increases in mean firm size/value added and decreases in mean firm wages (at pre-existing layers). The reverse holds for removing layers. This result also holds for layer by layer mean size and wages for a majority of pre-existing layers.

Support for prediction three is noisier than in CMRH because the Swedish occupation data for smaller firms is collected through rolling surveys (the data in CMRH covers the universe of workers). As smaller firms are not sampled every year, following hierarchical structures within firms over time substantially reduces the sample size.

\section{Data}

\subsection{The Swedish Occupation Data}

The Swedish Standard Classification of Occupations 1996 (SSYK) is a national version of the International Standard Classification of Occupations (ISCO) ISCO-88 (COM) standard of occupation classification developed for census and survey purposes. The SSYK data compiled for the Statistics Sweden LISA database comes primarily from two sources. The first is the official wage statistics survey (Lönestrukturstatistiken) which surveys around 11000 companies each year in the private sector. Companies with more than 500 workers are surveyed every year, the remainder is a random sample of firms. In total occupation data is gathered for around a million workers each year. The second source is a survey sent out by mail to around 30 000-47 000 companies per year in the private sector who are not selected for inclusion in the official wage statistics survey (a total of around 150000 private sector companies per year). The surveys are sent out on a rolling basis: all 150000 companies are surveyed at least once over a 4-5 year time span. Most of these companies have between 2 and 19 workers. In total, summing over the period 2001 to 2008, between 91 and 96 percent of all workers in Sweden are sampled at least once. 


\subsection{Data processing}

The sample is based on occupation data in the LISA database and firm accounting data from the Swedish Companies Registration Office available in the IFN Corporate Database (IFNCD). ${ }^{1}$ Data on occupation codes, firm-worker links, and labor income of workers comes from the LISA database. CMRH work with hourly wages and number of hours worked, however these are not available in my dataset. ${ }^{2}$ I proxy the workers wage with yearly labor income, which is the sum of an individuals before-tax labor income over the whole year, and hours of work with number of workers. Information on value added for all firms in the manufacturing sector comes from the IFNCD.

To merge the datasets, I start with the firm-level dataset for the years 2001 to 2007 and drop duplicated firm-year information (because multiple annual accounts can be submitted each year) and observations that have value added or size missing or non-positive. A firm is in the manufacturing sector if it has a SNI2002 categorization at the two digit level between 15 and 37 (the SNI2002 corresponds to the NACE classification at the four digit level). There are 139064 such firm-year observations.

Around $66 \%$ of the workers have accurate occupation data. "Accurate" means that the occupation information is collected the relevant year for the firm the worker-firm link refers to. ${ }^{3}$ Within a surveyed firm, not all workers have accurate occupation data. I keep only firm-year observations with more than $75 \%$ of all workers having accurate occupation data and trim away firm-year observations with labor income observations above the 99.95th percentile. The final dataset contains 39343 firm-year observations corresponding to $95 \%$ of value added and $68 \%$ of employment in the Swedish manufacturing sector.

\subsection{Constructing Layers of Management}

I follow CMRH and use the PCS-ESE classification as basis for layers of management. I use a PCS82 to ISCO-88 mapping and an ISCO-88 to SSYK96 mapping to go from PCS codes to SSYK codes. ${ }^{4}$ As $\mathrm{CMRH}$, I use the first digit of the PCS classification to group occupations into four classes. PCS Class 2 corresponds to firm owners receiving a wage (CEO and directors), PCS Class 3 to senior staff/top management positions, PCS Class 4 to supervisors and PCS Class $5+6$ to qualified and non-qualified clerical workers and blue collar workers. Table 1 displays the wage distribution across the PCS occupational categories as applied to the Swedish data. As in CMRH, workers in higher occupations (lower classes) tend to have higher mean and median wages in most parts of the wage distribution.

A firm-year observation with $c$ occupational categories will be said to have $L=c-1$ layers of management. For example, a firm containing two occupation classes will be said to have one layer of management (a firm can have a maximum of three layers of management).

Table 2 displays the number of firms per year as well as the mean value added, size, wage and layers. There is room for firms in the Swedish to change by adding or dropping layers as the average number

\footnotetext{
${ }^{1}$ See Tåg et al. (2013) for a closer description and summary statistics of the Swedish occupation classifications.

${ }^{2}$ Though not available to me, it is possible to obtain wage and hours data for a subsample of Swedish workers (those surveyed through "Lönestrukturstatistiken").

${ }^{3}$ For larger firms, the data comes from Lönestrukturstatistiken and is thus "accurate" for every year).

${ }^{4}$ Although the SSYK is based on ISCO-88 (COM), Statistics Sweden note that there are few differences between the ISCO88 and the ISCO-88 (COM) at the three digit level. The mapping from PCS82 to ISCO-88 comes from EurOccupations.org State-of-the-art report (First Reporting Period -D35) and the ISCO-88 to SSYK96 mapping from Statistics Sweden. When the PCS code corresponds to two or more ISCO-88 codes, I use the highest code (lowest rank) of the ISCO codes for that PCS code.
} 
Table 1: Wage distribution

\begin{tabular}{lcccccccc}
\hline \hline PCS & Mean & p5 & p10 & p25 & p50 & p75 & p90 & p95 \\
\hline Class 5+6 & 267.1 & 122.4 & 168.4 & 219.2 & 262.5 & 311.4 & 366.7 & 409.4 \\
Class 4 & 348.1 & 158.7 & 201.6 & 255.9 & 325.3 & 418.1 & 529.3 & 606.5 \\
Class 3 & 475.3 & 216.7 & 263.6 & 333.3 & 426.2 & 554.3 & 735.2 & 887.5 \\
Class 2 & 520.9 & 156 & 198.1 & 261.7 & 359.7 & 594.7 & 999.3 & $1,359.30$ \\
\hline Full sample & 307.7 & 132.5 & 179.5 & 229.1 & 279.9 & 349.7 & 458.5 & 557.5 \\
\hline \hline
\end{tabular}

Notes. This table shows the wage distribution across the four PCS classes that form the basis of layers of management in a firm. The table corresponds to Table 1 in CMRH. Wages are in thousands of 2005 SEK.

Table 2: Sample by year

\begin{tabular}{cccccc}
\hline \hline Year & $\begin{array}{c}\text { Firm-year } \\
\text { observations }\end{array}$ & $\begin{array}{c}\text { Value } \\
\text { added }\end{array}$ & $\begin{array}{c}\text { Average } \\
\text { size }\end{array}$ & $\begin{array}{c}\text { Average } \\
\text { wage }\end{array}$ & $\begin{array}{c}\text { Average layers of } \\
\text { management }\end{array}$ \\
\hline 2001 & 7581 & 32378.20 & 42.1 & 218.6 & 1.2 \\
2002 & 7444 & 37368.60 & 47.7 & 233.7 & 1.4 \\
2003 & 4839 & 60426.40 & 70.0 & 249.2 & 1.4 \\
2004 & 4207 & 72412.40 & 75.8 & 259.7 & 1.5 \\
2005 & 3822 & 88274.80 & 84.0 & 271.7 & 1.6 \\
2006 & 4999 & 76265.40 & 66.2 & 281.4 & 1.4 \\
2007 & 6122 & 68445.90 & 60.2 & 297.8 & 1.5 \\
\hline Total & 39014 & 57885.30 & 60.3 & 255.4 & 1.4 \\
\hline \hline
\end{tabular}

Notes. This table shows how the sample is spread out over time. It corresponds to Table 2 in CMRH. Value added and wage is in thousands of 2005 SEK.

of layers in the firm is similar to CMRH (ranging from 1.2 to 1.6 here and 1.50 to 1.59 in CMRH). The sample size, however, varies quite a bit across time as a result of changes in the sampling of occupations of workers in smaller firms. ${ }^{5}$

\section{Analysis}

The hierarchies constructed in the data corresponds to the theoretical predictions of CMRH and CRH, although the data is noisier than in CMRH. The following three results are all broadly in line with the findings of CMRH for French production hierarchies.

First, firms with more layers are larger in size, in value added, and pay higher wages. This is apparent from Table 3, which shows the mean of value added, size, and wage across firms with different number of layers.

Second, firms are hierarchal in that lower layers have on average more workers and lower mean wage than higher layers. Table 4 displays the share of firm-year observations for which a layer of management is smaller in size and has a higher average wage than the layer of management below it. The percentages

\footnotetext{
${ }^{5}$ Note that firms do not appear to have become flatter over time as in CMRH for France or Rajan and Wulf (2006) for the US. This, however, is likely an artifact of the changes in average size and value added across years because of the sampling of the occupation data.
} 
Table 3: Sample by layer

\begin{tabular}{lcrcll}
\hline \hline Layers & Firm-years & \multicolumn{1}{c}{ Mean VA } & Mean Size & Mean Wage & Median Wage \\
\hline 0 & 10347 & 2514.70 & 4.7 & 223.2 & 218.1 \\
1 & 10908 & 6363.80 & 10.2 & 241.9 & 234.9 \\
2 & 9361 & 46092.70 & 55.4 & 269.9 & 261.4 \\
3 & 8398 & 206171.30 & 199.1 & 296.5 & 287.1 \\
\hline Full sample & 39014 & 57885.30 & 60.3 & 255.4 & 249.8 \\
\hline \hline
\end{tabular}

Notes. This table displays the sample across layers of management (it corresponds to Table 3 in CMRH). Wages and value added (VA) is in thousands of 2005 SEK.

Table 4: Hierarchy in size and wage

\begin{tabular}{lllllll}
\hline \hline Layers & \multicolumn{2}{l}{ Size of layers } & & \multicolumn{3}{c}{ Mean wage in layers } \\
\hline & $0 \geq 1$ & $1 \geq 2$ & $2 \geq 3$ & $0 \geq 1$ & $1 \geq 2$ & $2 \geq 3$ \\
\hline 1 & $95 \%$ & & & $82 \%$ & & \\
2 & $89 \%$ & $79 \%$ & & $82 \%$ & $82 \%$ & \\
3 & $88 \%$ & $70 \%$ & $95 \%$ & $87 \%$ & $87 \%$ & $88 \%$ \\
\hline \hline
\end{tabular}

Notes. This table displays the percentage of firms that satisfy a hierarchy in number of workers and in average wages (corresponding to Table 5 and 6 in $\mathrm{CMRH}$ ).

in Table 4 are similar to the percentages in CMRH, which vary between $54.3 \%$ and $85.3 \%$ for hours of work and $79.7 \%$ and $96.5 \%$ for wages. Figure 1 illustrates the pattern on average for all hierarchy sizes. For each hierarchy size, the mean size of the lower layers is larger than that of the higher layers, and the mean wage of the lower layers is lower than that of the higher layers.

Third, adding layers is on average associated with increases in mean firm size and decreases in mean firm wages (at pre-existing layers) and the reverse holds for removing layers. This also holds for layer by layer mean size and wages for a majority of pre-existing layers. Table 5 show the results from computing the log change in total number of workers, value added and mean wage at the firm level separately for firms that increase the number of layers, has no change in the number of layers, or decreases the number of layers. ${ }^{6}$ It is based on the 12340 firm-year observations (31\% of the sample) that have two subsequent observations. Adding layers is correlated with increases in size, value added, and mean wages. After detrending the data, removing layers is correlated with reductions in size, value added, and mean wage. However, consistent with $\mathrm{CMRH}$ and the theorethical predictions in $\mathrm{CRH}$, mean wages at pre-existing layers fall when adding layers and increases when removing layers (after detrending). The share of firms with no change in number of layers is around the same (76\%) as in CMRH (73\%), but stand for a larger share of change in total value added (90\%) than in CMRH (65\%). This is likely due to the sampling occupations being biased towards larger firms that see fewer changes in layers. The average effects of changing layers on the mean size and wage in pre-existing layers holds for a majority of individual pre-existing layers as well. CMRH finds that this holds for all pre-existing layers in the French data. Here, however, because so few firms are sampled two years in a row the results are less clear. Table

\footnotetext{
${ }^{6}$ The reasons for the large reduction in the number of the rolling panel feature of the way occupation data is collected.
} 

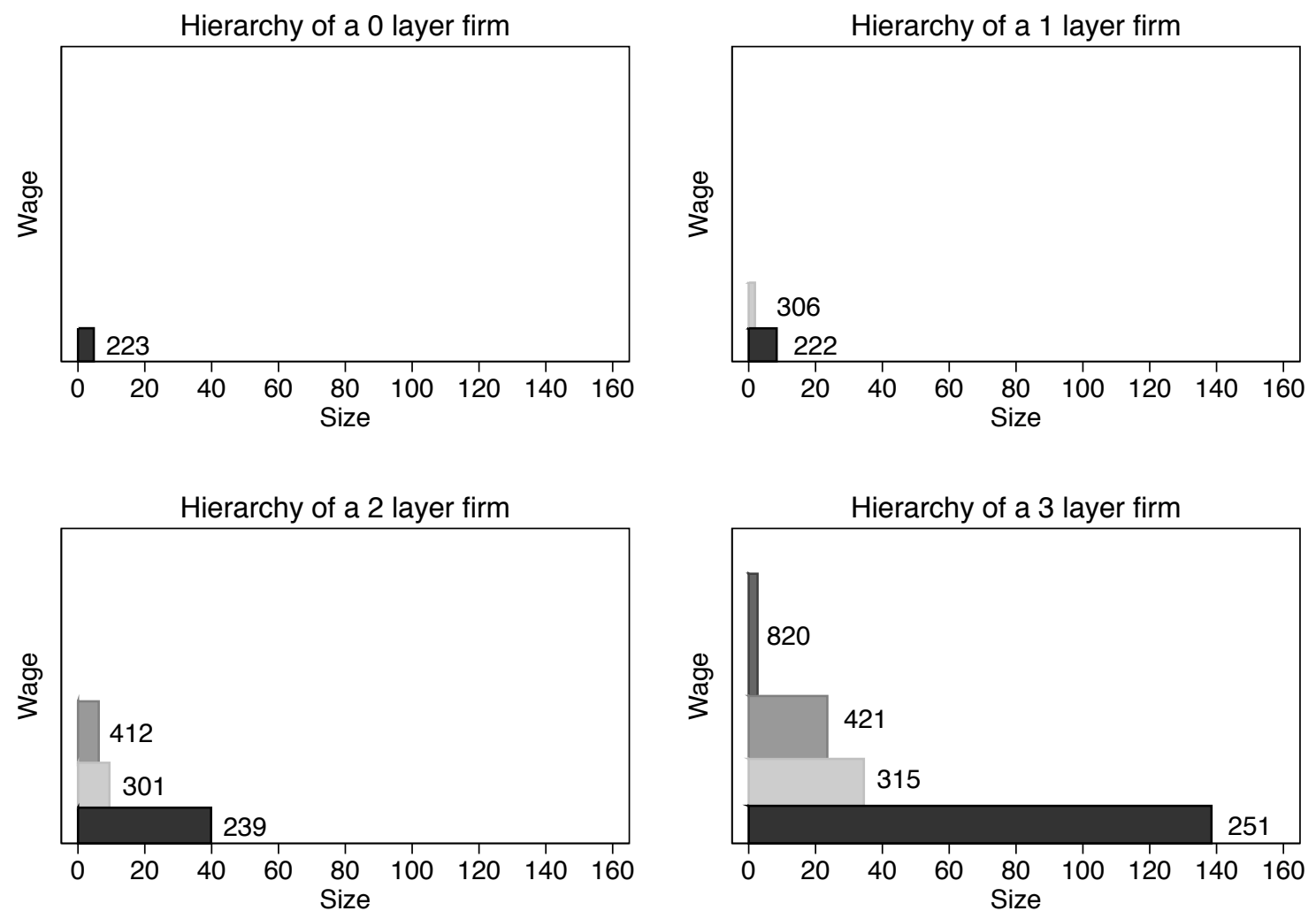

Figure 1: Size and average wage

Notes. This figure displays the mean size and mean wage in each layer of management for all four possible hierarchies (replicating Figure 5 in $\mathrm{CMRH}$ ). The width of a box corresponds to the mean size of a layer (given on the $\mathrm{x}$-axis). The height corresponds to the mean wage in the layer (given next to the box in thousands of 2005 SEK). 
Table 5: Change in firm level outcomes.

\begin{tabular}{lcccc}
\hline \hline Variable & All & Increase & No change & Decrease \\
\hline$\Delta \log ($ size $)$ & $-0.006^{* *}$ & $0.105^{* * *}$ & $-0.006^{* *}$ & $-0.114^{* *}$ \\
- detrended & & $0.112^{* * *}$ & -0.001 & $-0.107^{* * *}$ \\
$\Delta \log ($ value added $)$ & $0.058^{* * *}$ & $0.102^{* * *}$ & $0.057 * * *$ & $0.023^{* *}$ \\
- detrended & & $0.045^{* * *}$ & -0.002 & $-0.034 * * *$ \\
$\Delta \log ($ wage $)$ & $0.056^{* * *}$ & $0.080^{* * *}$ & $0.055^{* * *}$ & $0.043^{* * *}$ \\
- detrended & & $0.024 * * *$ & -0.001 & $-0.014 * *$ \\
- common & $0.056^{* * *}$ & $0.030^{* * *}$ & $0.055^{* * *}$ & $0.093^{* * *}$ \\
- common detrended & & $-0.026^{* * *}$ & -0.001 & $0.037^{* * *}$ \\
\hline$\%$ of firms & & $12 \%$ & $76 \%$ & $12 \%$ \\
$\%$ of $\Delta($ value added $)$ & & $5 \%$ & $90 \%$ & $5 \%$ \\
\hline \hline
\end{tabular}

Notes. This table displays the change in firm size, value added, and mean wage for firms that add layers (increase), do not change layers (no change), or remove layers (decrease). It corresponds to Table 13 in CMRH. Statistical significance is given at the $1 \%(* *), 5 \%(* *)$, and $10 \%(*)$ level and is based on a t-test of the change in logs being different from zero. Detrending is done by substracting the mean of yearly changes in the log of the variables.

6 displays the mean change in the log of normalized layer size and mean change in the log of mean wage at a layer for different transitions (based on the firms that change layers out of the $31 \%$ that can be observed for two consecutive years). A total of $57.5 \%$ of the estimates give statistically significant results corresponding to $\mathrm{CMRH}$ and $32.5 \%$ provide statistically significant results opposite to CMRH.

\section{Final Remarks}

Researchers interested in working directly with the Swedish occupation data could be interested in how to directly construct hierarchies from SSYK occupation codes. The results presented above are similarsometimes even stronger-using the following SSYK occupation classification:

Class 3: CEOs and directors: SSYK 121 (Directors and chief executives), 131 (Managers of small enterprises), 111 (legislators and senior government officials), and 112 (senior officials of specialinterest organizations)

Class 2: Senior staff: SSYK 122 (Production and operations managers), 123 (Other specialist managers)

Class 1: Supervisors: SSYK 200-399 (Professionals, technicians and associate professionals)

Class 0: Clerks and blue-collars: SSYK 400-999 (Clerks, Service workers and shop sales workers, skilled agricultural and fishery workers, craft and related trades workers, plant and machine operators and assemblers, and elementary occupations).

This classification is useful outside of the production sector as well. Tåg et al. (2013) uses data on all sectors in the Swedish economy and shows that this classification generates hierarchical structures that correspond to theoretical predictions. 
Table 6: Changes in layers across transitions

\begin{tabular}{|c|c|c|c|c|c|c|c|}
\hline \multicolumn{3}{|c|}{ Layers } & \multicolumn{2}{|c|}{ Size } & \multicolumn{2}{|c|}{ Wage } & \multirow[t]{2}{*}{ Obs. } \\
\hline Before & After & Layer & $\Delta \log ($ size $)$ & p-value & $\Delta \log ($ wage $)$ & p-value & \\
\hline 0 & 1 & 0 & -0.542 & 0.000 & 0.015 & 0.361 & 231 \\
\hline 0 & 2 & 0 & -0.405 & 0.007 & 0.044 & 0.022 & 49 \\
\hline 0 & 3 & 0 & -0.386 & 0.733 & -0.238 & 0.198 & 7 \\
\hline 1 & 0 & 0 & 0.338 & 0.000 & 1.141 & 0.000 & 260 \\
\hline 1 & 2 & 0 & 0.281 & 0.000 & 0.023 & 0.016 & 396 \\
\hline 1 & 2 & 1 & -0.385 & 0.000 & -0.074 & 0.000 & 396 \\
\hline 1 & 3 & 0 & 0.688 & 0.000 & 0.013 & 0.454 & 77 \\
\hline 1 & 3 & 1 & -0.315 & 0.047 & -0.149 & 0.001 & 77 \\
\hline 2 & 0 & 0 & 0.360 & 0.063 & 0.146 & 0.000 & 52 \\
\hline 2 & 1 & 0 & -0.395 & 0.000 & 0.085 & 0.000 & 383 \\
\hline 2 & 1 & 1 & 0.471 & 0.000 & 0.231 & 0.000 & 383 \\
\hline 2 & 3 & 0 & 1.174 & 0.000 & 0.047 & 0.000 & 696 \\
\hline 2 & 3 & 1 & 1.186 & 0.000 & 0.030 & 0.000 & 696 \\
\hline 2 & 3 & 2 & -0.120 & 0.002 & -0.059 & 0.000 & 696 \\
\hline 3 & 0 & 0 & -0.047 & 0.000 & 0.035 & 0.000 & 10 \\
\hline 3 & 1 & 0 & -0.743 & 0.000 & 0.096 & 0.000 & 70 \\
\hline 3 & 1 & 1 & 0.0370 & 0.001 & 0.217 & 0.000 & 70 \\
\hline 3 & 2 & 0 & -1.356 & 0.000 & 0.069 & 0.000 & 697 \\
\hline 3 & 2 & 1 & -1.329 & 0.000 & 0.083 & 0.000 & 697 \\
\hline 3 & 2 & 2 & 0.140 & 0.000 & 0.145 & 0.000 & 697 \\
\hline
\end{tabular}

Notes. Mean change in log of normalized layer size and wage for different transitions. The first and second columns show how layers of management change in the firm, while the third column gives the layer that the remaining columns refer to. This table replicates Tables 14 and 15 in CMRH. Bolded correspond to statistically significant results in line with CMRH, emphasized to statistically significant results opposite to CMRH. Statistical significance is given at the $1 \%(* * *), 5 \%(* *)$ and $10 \%(*)$ level. The p-values are obtained from a regression of the change in log normalized layer size or log wage on a constant (with robust standard errors). The final column reports the number of observations in the regression. Normalization of layer size is done by dividing the size of the layer with the size of the top layer of management. 


\section{References}

Caliendo, L., F. Monte, and E. Rossi-Hansberg (2012). The Anatomy of French Production Hierarchies. NBER Working Paper 18259, 1-75.

Caliendo, L. and E. Rossi-Hansberg (2012). The Impact of Trade on Organization and Productivity. The Quarterly Journal of Economics 127(3), 1393-1467.

Garicano, L. (2000). Hierarchies and the Organization of Knowledge in Production. Journal of Political Economy 108(5), 874-904.

Garicano, L. and E. Rossi-Hansberg (2006). Organization and Inequality in a Knowledge Economy. The Quarterly Journal of Economics 121(4), 1383-1435.

Rajan, R. G. and J. Wulf (2006). The Flattening Firm: Evidence from Panel Data on the Changing Nature of Corporate Hierarchies. Review of Economics and Statistics 88(4), 759-773.

Tåg, J., T. Åstebro, and P. Thompson (2013). Hierarchies, the Small Firm Effect, and Entrepreneurship: Evidence from Swedish Microdata. IFN Working Paper 954, 1-32. 